Research Article

\title{
Repeated Low-Intensity Shock Wave Simulation Experiment for Fracture Development and Propagation of Coal
}

\author{
Taofeng Xie $\mathbb{D}^{D}$, Xiaoting Zhou $\mathbb{D}^{D}$, Qingya Wang ${ }^{\mathbb{D}}$, Shuai Cao $\mathbb{D}$, Huiming Cao $\mathbb{D}$, \\ and Wengang Huang
}

School of Earth Science East China University of Technology, Nanchang 330013, Jiangxi, China

Correspondence should be addressed to Xiaoting Zhou; tingtingmumu@126.com

Received 5 December 2018; Revised 25 March 2019; Accepted 10 April 2019; Published 26 May 2019

Academic Editor: Isabelle Sochet

Copyright (c) 2019 Taofeng Xie et al. This is an open access article distributed under the Creative Commons Attribution License, which permits unrestricted use, distribution, and reproduction in any medium, provided the original work is properly cited.

\begin{abstract}
For low-permeability coal seam, the gas extraction rate is relatively low. The repeated low-intensity shock wave can improve the permeability of coal and raise the rate of coal seam gas drainage. A simulation test platform was set up to carry out repeated low-intensity shock wave simulation experiment. Under the effect of repeated low-intensity shock wave, the development process of the macrofracture, pore evolution, and the law of microcrack propagation was analyzed to study the law of coal fracture propagation. Research shows that the expansion of the pore of the coal is made by the development of large, medium, and micropores by the repeated low-strength shock wave. The main contribution of the total pore volume increase comes from the micropore growth. The microcrack of the coal mainly begins to sprout and develops from the telocollinite where the fracture is more developed. With the increase of impact times, the microcracks extend to other components. Under the impact of different times, the fractal dimension of the coal sample increases with the increase in the number and length of cracks.
\end{abstract}

\section{Introduction}

Improving the permeability of coal seam and increasing gas drainage have always been the main research direction of gas disaster control and gas resource extraction technology $[1,2]$. Hydraulic sand fracturing is the main measure to improve permeability of coal seam at present [3-6]. However, due to its own characteristics, the fracturing effect is severely constrained by the conditions of the coal seam. Many injuries caused by fracturing to coal seams will affect subsequent mining, reduce production efficiency, and increase production costs [7-10]. It is an effective method to improve the efficiency of gas extraction by adopting explosions increasing permeability of coal seam [11-13]. Deyong et al. applied deep hole energy blasting technology to increase the permeability of the coal seam [14]. Ren et al. developed high-voltage electrohydraulic discharge (EHD) [15]. Strong pressure shock waves were generated by underwater electrical discharges or high energy explosion, which then served to damage the associated solids, creating fractures and cracks. But the secondary disasters such as roof fall were easily caused by strong pressure shock waves [16-18].

$\mathrm{Xu}$ et al. used the explosive fracturing experiment device developed by them to carry out the explosive fracturing simulation experiment for low-permeability reservoir and analyze the growth of the cracks produced by the explosive fracturing in the samples [19]. Lin et al. studied the phenomenon of the rock damage and fracture by the shock wave of exploding in fractures via the experiment of exploding on the surface of the cement sample in deep water [20].

The permeability of the coal seam can be increased in a softer way by using repeated low-intensity shock wave. By establishing a simulation test platform, we simulated the law of coal rock fracture expansion under repeated low-strength shocks and further studied the mechanism of coal cracking, 
which provides a basis for optimizing the parameters and analyzing the effects of increasing permeability of coal under repeated low-strength impact.

\section{Materials and Methods}

To study the influence of the low-intensity shock wave on fracture development of coal fissure and pore, repeated lowintensity impact tests were carried out on the coal samples under three kinds of low-intensity shock wave loading conditions using a self-built experimental platform under the condition of no confining pressure.

2.1. Experimental Device. The low-intensity explosion impact simulation experiment device mainly consists of three parts, such as a water tank $(1.2 \mathrm{~m} \times 1.2 \mathrm{~m} \times 1.2 \mathrm{~m}$ in size, water depth $0.8 \mathrm{~m}$ ), a simulated shock wave generator, and a shock wave pressure sensor (Figure 1). The simulated drilling casing size is $139.7 \mathrm{~mm}$, the hole density is 60 holes per metre, and the hole diameter is $10 \mathrm{~mm}$. The shock wave generating device triggers the energetic bomb with electric energy to form a low-intensity shock wave. The shock wave pressure sensor is fixed on the water tank. The probe position is parallel to the center point of the shock wave generating window, and the distance is $300 \mathrm{~mm}$.

We use the small pieces dropped during the impact process under different impact times to make a polished block $(0.3 \mathrm{~m} \times 0.3 \mathrm{~m} \times 0.3 \mathrm{~m}$ in size $)$ and use NIS-Elements Documentation optical microscope for quantitative observation (Figure 2). The NIS-Elements Documentation optical microscope has the function of phototaking and splicing.

2.2. Properties of Coal Samples. The sample of the experimental coal was taken from No. 7 coal seam of Wulan Coal Mine in Hulusitai Mining Area of Ningxia, which belongs to fat coal. Proximate analysis, determination of reflectance of mirror mass, and quantitative experiments on the microscopic composition are carried out on coal samples. The basic properties of coal samples are shown in Table 1.

The large coal samples were cut into samples of $30 \mathrm{~cm} \times 30 \mathrm{~cm} \times 30 \mathrm{~cm}$ size along parallel and vertical lamination directions and polished, and then the cut scratches were removed. The shock wave loading positions of all samples are facing the center area of plane B (Figure 3 ).

2.3. Mechanical Properties of Shock Wave. The shock waveforms were measured during the experiment in the case of $5 \mathrm{~g}, 10 \mathrm{~g}$, and $15 \mathrm{~g}$ energetic projectiles (Figure 4). The trend of attenuation of all waveforms is basically similar. And the impact is instantaneous. The impact pressure becomes more than $4 \mathrm{MPa}$ within $0.1 \mathrm{~ms}$ and instantly becomes $0 \mathrm{MPa}$. The maximum peak pressure at $5 \mathrm{~g}$ energetic bombs is $4.0 \mathrm{MPa}$, at $10 \mathrm{~g}$ energetic bomb is $5.0 \mathrm{MPa}$, and at $15 \mathrm{~g}$ energetic bomb is $5.4 \mathrm{MPa}$.

2.4. Approaches and Processing Procedures. The processed coal sample needs to be immersed in the tap water for
72 hours, simulating the impact work environment of the saturated water coal to reduce the influence of water environment error on the process and degree of coal sample rupture. In order to prevent the coal from falling into the water due to cracking during the impact, a metal mesh with a mesh size of $10 \mathrm{~mm} \times 10 \mathrm{~mm}$ was used to wrap the coal block. Then, the coal block was immersed in the water tank along the parallel bedding direction, and the occurrence window of the shock wave was consistent with the central position of the coal sample. The distance between coal sample and shock wave source is $100 \mathrm{~mm}$. Different intensity shock waves were simulated with $5 \mathrm{~g}, 10 \mathrm{~g}$, and $15 \mathrm{~g}$ bombs, respectively. The power supply of the power control cabinet to generate an explosion shock wave was turned on. Then, the power supply was turned off, and the shock wave pressure detected by the oscilloscope was saved. The coal block breakage was checked, and a coal sample impact experiment was completed.

The experiment step was repeated, and the coal block was placed out of the water tank at certain impact times. The surface of the coal body was photographed and sampled. The entire process was repeated until the coal sample was broken, and the experiment was ended.

\section{Results and Discussion}

Coal is a three-element porous medium composed of macroscopic fissure, microfissure, and pore. Microfissure is the bridge between pore and fissure. Pore and fissure are discontinuous spaces in coal rock, which determine the permeability of coal rock fissure [21].

3.1. Analysis of Growth of Macrocracks. Under the action of different energy shock waves, the law of fracture generation and propagation of the coal body is approximately the same, all of which are around the primary crack to further expand and develop. Finally, the coal structure ruptures and disintegrates (Figure 5).

At first, the number of cracks slowly increased, and the cracks mainly extended from the end of the cracking. Then, the fissure increases rapidly, mainly by open fork hyperplasia, and it showed that the crack width increased and the coal body broke. The complexity of the crack network tended to maximize, and the connectivity between the cracks increased. It can be seen from the law of macroscopic crack expansion that, with the increase of the number of shocks, the degree of coal fracture gradually deepened and finally disintegrated. All experimental coal samples were fractured and disintegrated after 8 impacts. There is a threshold in the number of shocks. If the number of shocks exceeds the threshold, the coal body will be destroyed rapidly, and the macrocracks will increase obviously. Before that, the coal has been in the period of fracture incubation under the impact.

3.2. Pore Evolution Law. The pore structure changes of coal samples F1 and F2 under the impact of $5 \mathrm{~g}$ and $10 \mathrm{~g}$ energetic shock waves before and after loading were studied by means of mercury injection experiments. The mercury injection 

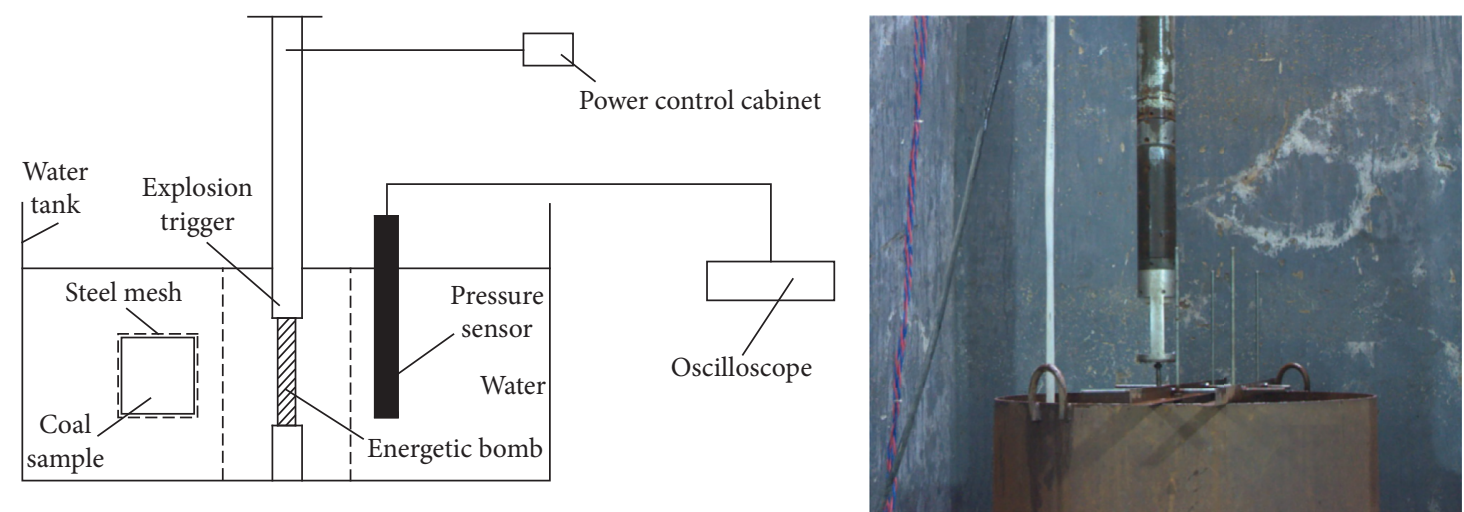

(a)

(b)

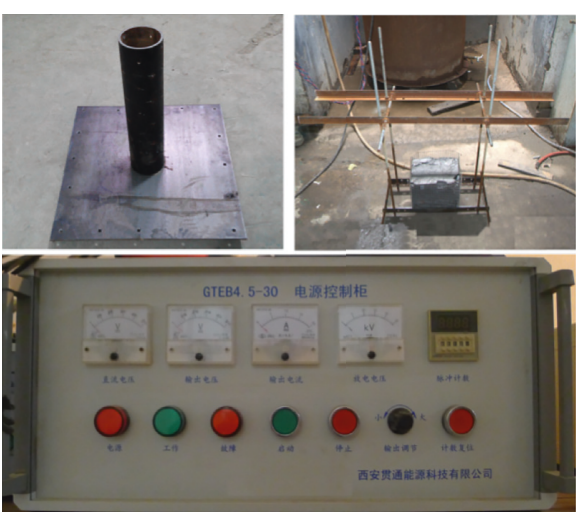

(c)

FIGURE 1: Schematic diagram of an experimental device.

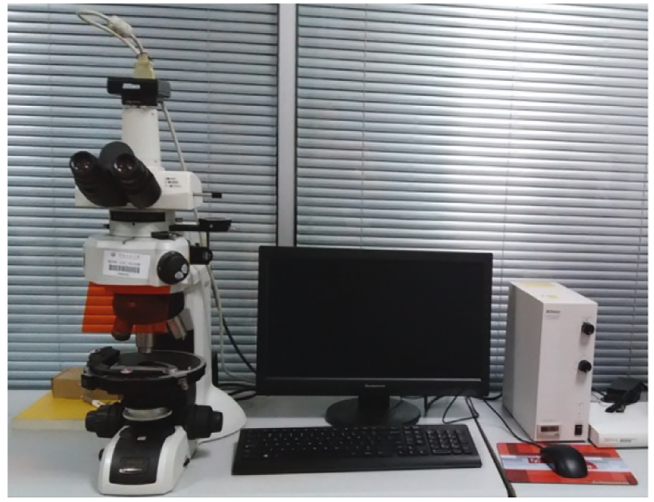

(a)

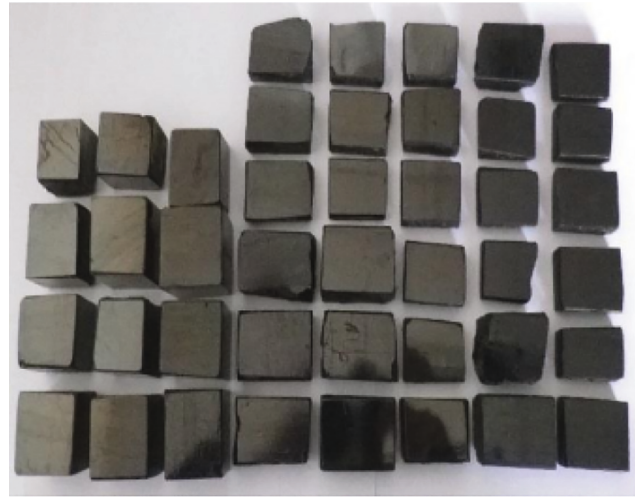

(b)

FIgURE 2: Microphotometer and polished lump coal section: (a) NIS-Elements Documentation optical microscope; (b) polished block.

Table 1: Coal sample and basic properties.

\begin{tabular}{|c|c|c|c|c|c|c|c|c|}
\hline \multirow{2}{*}{ Coal rank } & \multirow{2}{*}{ Sampling sites } & \multirow{2}{*}{ Sample } & \multirow{2}{*}{$R_{0, \max }(\%)$} & \multicolumn{3}{|c|}{ Proximate analysis } & \multirow{2}{*}{ Permeability (md) } & \multirow{2}{*}{ Porosity (\%) } \\
\hline & & & & $M_{\mathrm{ad}}(\%)$ & $A_{\mathrm{d}}(\%)$ & $V_{\text {daf }}(\%)$ & & \\
\hline \multirow{3}{*}{ Fat coal } & \multirow{3}{*}{ Wulan coal mine } & $\mathrm{F} 1$ & 1.18 & 0.86 & 6.42 & 35.21 & 0.025 & 3.43 \\
\hline & & $\mathrm{F} 2$ & 1.19 & 1.03 & 4.71 & 29.70 & 0.105 & 3.99 \\
\hline & & F3 & 1.17 & 1.30 & 5.81 & 29.68 & 0.065 & 3.85 \\
\hline
\end{tabular}




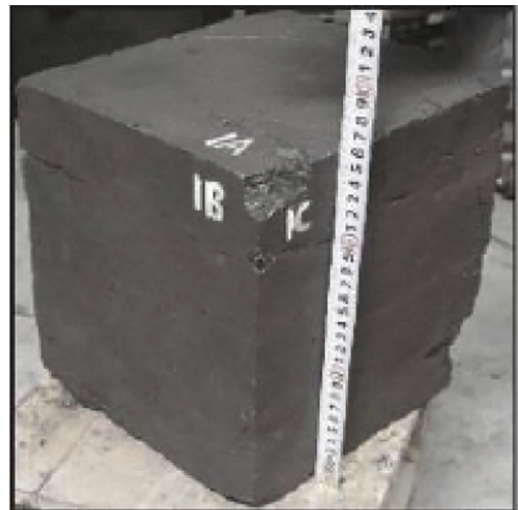

(a)

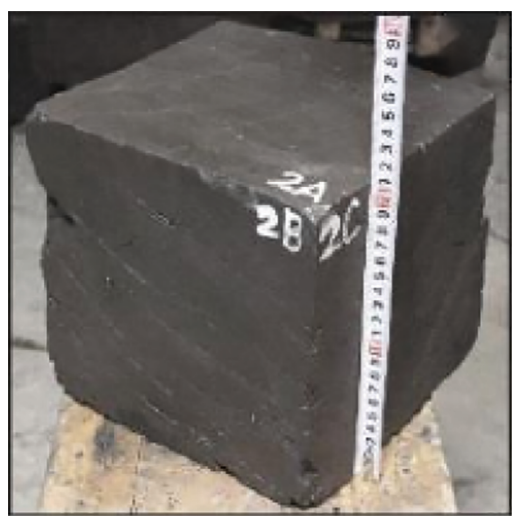

(b)

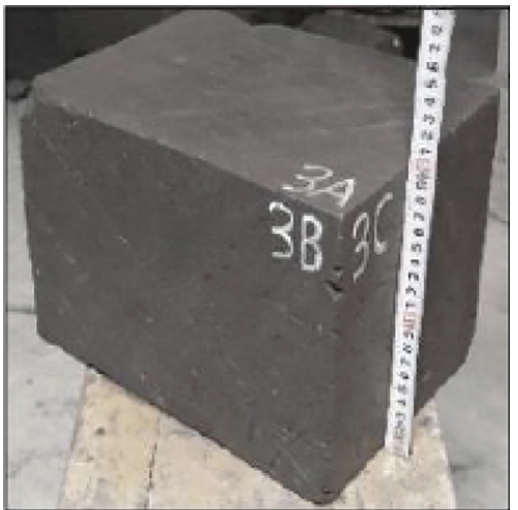

(c)

Figure 3: Photos of coal samples: (a) F1; (b) F2; (c) F3.

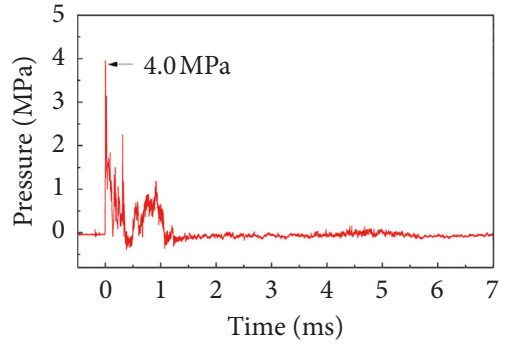

(a)

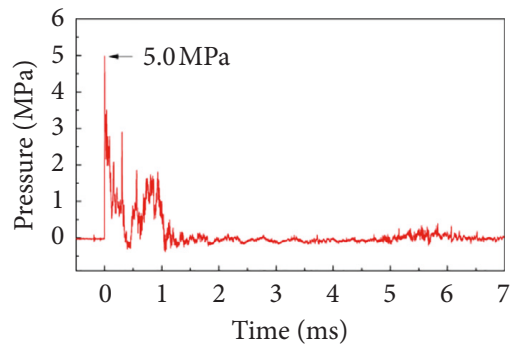

(b)

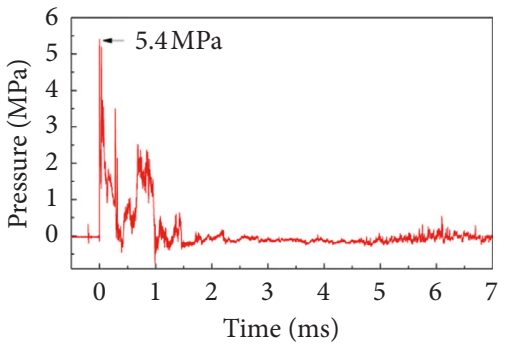

(c)

Figure 4: Waveforms of electric pulse wave: (a) $5 \mathrm{~g}$ energetic bomb; (b) $10 \mathrm{~g}$ energetic bomb; (c) $15 \mathrm{~g}$ energetic bomb.

experiment results of the pore structure of the sample are shown in Table 2 . The aperture structure is divided by B. B. Hodort's decimal scheme (micropores $<10 \mathrm{~nm}$, small pores $10-100 \mathrm{~nm}$, medium pores $100-1000 \mathrm{~nm}$, and large pores $>1000 \mathrm{~nm}$.).

Under the action of repeated shock waves, the expansion of coal pores was alternated between the development of large and medium pores and micropores and small pores. The increase of pore volume at each stage is due to the transformation of smaller pore size into larger pore size. The fluctuation degree of the pore volume of the large and medium pores and the micropores and small pores with the number of impacts reflects the degree of adjustment of the pore structure during the shock wave action. The greater the degree of fluctuation, the stronger the impact of the explosive shock wave on the pore structure of coal body, and the more favorable the pore improvement (Figure 6).

3.3. Evolution Law of Fracture Propagation. The development of microcracks in coal samples F1 and F3 with different energies and impact times under the action of low-intensity explosion shock waves was counted [14], and the results are shown in Table 3. The development of microcracks was described and analyzed by using the results of the double objective lens of the polished block under different loading conditions.
As shown in Figure 7, under the action of the explosive shock wave of $5 \mathrm{~g}$ or $15 \mathrm{~g}$ energetic bomb, the microcracks of coal samples mainly began to germinate and develop from the telocollinite with more developed cracks. And with the increase of impact times, it expanded to other components. The boundaries of the components of the fat coal are clear, and there are a lot of telocollinite bands in fat coal. In the early stages of the impact, it was mainly short and small fissure development. With the increase of impact times, cracks expanded through components and connected to each other. The length of cracks continued to increase.

As shown in Figures 8 and 9, under the impact of coal samples, linear density and areal density of microfissure increased significantly and showed a good trend of fracture development.

3.4. Permeability. The air permeability of 3 coal samples was tested to study the effect of the shock wave on the coal seam. After the experiment, the porosity and permeability of coal were higher than the original coal samples. The three coal samples were impacted 10 times with $5 \mathrm{~g}, 10 \mathrm{~g}$, and $15 \mathrm{~g}$ energy bombs, respectively, and the permeability of the coal body increased significantly. Under the impact of $15 \mathrm{~g}$ energy bombs, the permeability of the coal body increased by more than 12 times (Figure 10). 

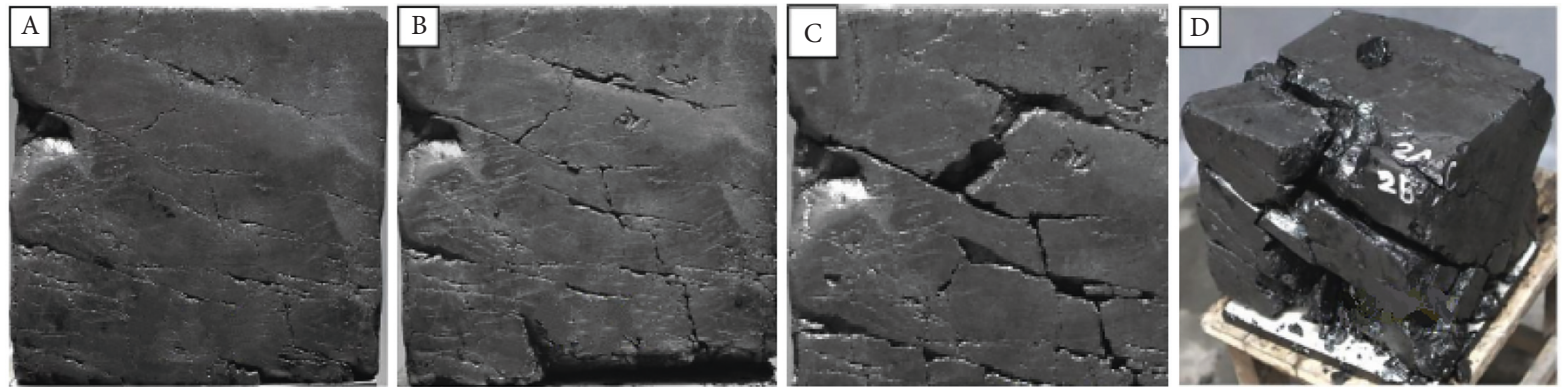

(a)
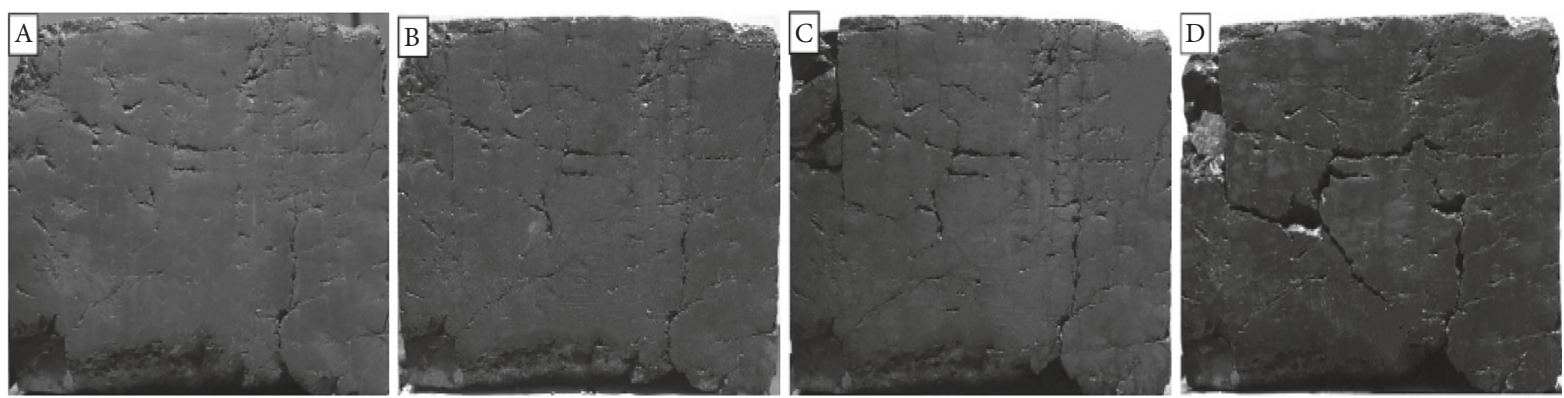

(b)
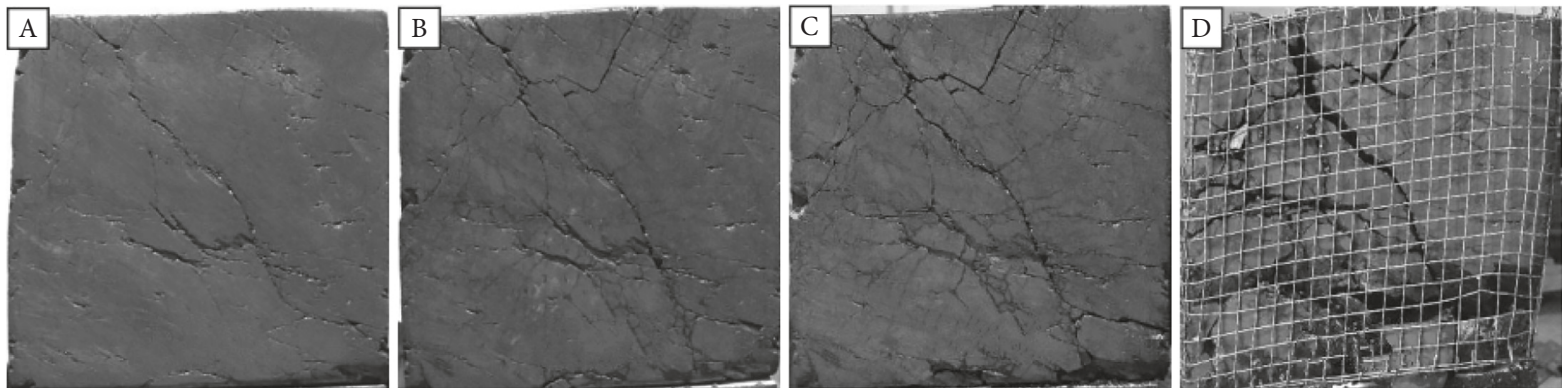

(c)

Figure 5: Development of macroscopic cracks: (a) F1; (b) F2; (c) F3. (A) Impact 0 times; (B) impact 2 times; (C) impact 6 times; (D) impact 8 times.

TABLE 2: Pore structure parameters of fat coals by using mercury intrusion porosimetry.

\begin{tabular}{|c|c|c|c|c|c|c|c|c|}
\hline \multirow[b]{2}{*}{ Loading conditions } & \multirow[b]{2}{*}{ Sample } & \multirow{2}{*}{$\begin{array}{l}\text { Impact } \\
\text { number }\end{array}$} & \multirow{2}{*}{$\begin{array}{l}\text { Total pore volume } \\
\qquad\left(10^{-4} \mathrm{~cm}^{3} / \mathrm{g}\right)\end{array}$} & \multirow{2}{*}{$\begin{array}{l}\text { Porosity } \\
\text { (\%) }\end{array}$} & \multicolumn{4}{|c|}{ Pore volume $\left(10^{-4} \mathrm{~cm}^{3} / \mathrm{g}\right)$} \\
\hline & & & & & $\begin{array}{l}\text { Large } \\
\text { pores }\end{array}$ & $\begin{array}{c}\text { Medium } \\
\text { pores }\end{array}$ & $\begin{array}{l}\text { Small } \\
\text { pores }\end{array}$ & Micropores \\
\hline \multirow{6}{*}{$\begin{array}{l}5 \mathrm{~g} \text { energetic } \\
\text { projectiles }\end{array}$} & F1-0 & 0 & 334 & 3.99 & 29 & 14 & 98 & 193 \\
\hline & F1-2 & 2 & 339 & 4.01 & 44 & 17 & 94 & 184 \\
\hline & F1-4 & 4 & 339 & 4.30 & 58 & 16 & 89 & 176 \\
\hline & F1-6 & 6 & 351 & 4.07 & 38 & 13 & 102 & 198 \\
\hline & $\mathrm{F} 1-8$ & 8 & 332 & 4.03 & 48 & 15 & 90 & 179 \\
\hline & $\mathrm{F} 1-10$ & 10 & 379 & 4.37 & 47 & 9 & 108 & 215 \\
\hline \multirow{6}{*}{$\begin{array}{l}10 \text { g energetic } \\
\text { projectiles }\end{array}$} & $\mathrm{F} 2-0$ & 0 & 313 & 3.85 & 30 & 17 & 95 & 171 \\
\hline & $\mathrm{F} 2-2$ & 2 & 355 & 3.92 & 47 & 14 & 105 & 189 \\
\hline & $\mathrm{F} 2-4$ & 4 & 333 & 3.99 & 27 & 14 & 101 & 191 \\
\hline & F2-6 & 6 & 379 & 4.39 & 54 & 17 & 108 & 200 \\
\hline & F2-8 & 8 & 356 & 4.18 & 54 & 18 & 100 & 184 \\
\hline & F2-10 & 10 & 354 & 3.98 & 31 & 15 & 107 & 201 \\
\hline
\end{tabular}



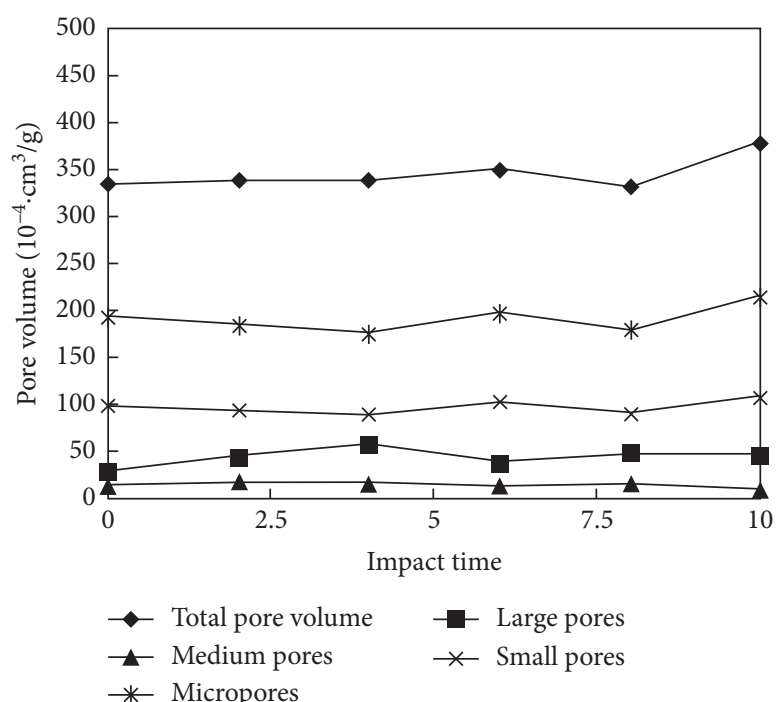

(a)

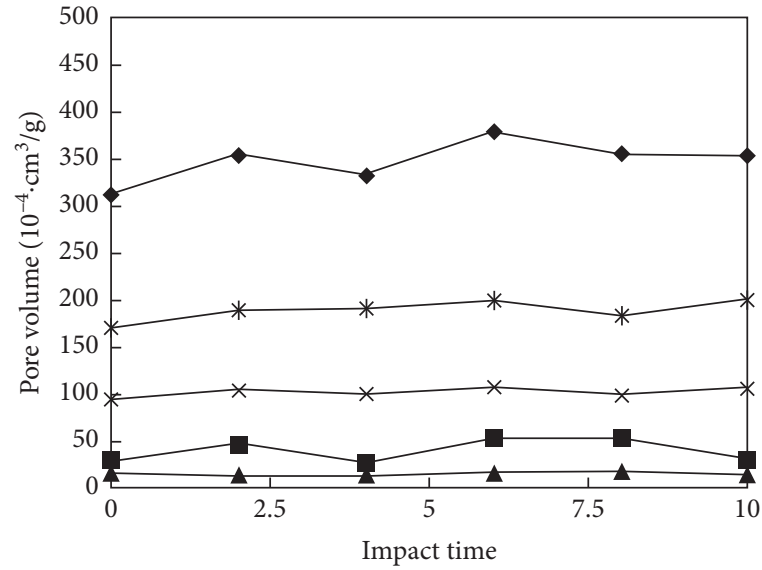

$\multimap$ Total pore volume

$\neg$ Medium pores

- Large pores

$*$ Small pores

* Micropores

(b)

FIGURE 6: Plots of pore volume to shock times for fat coal samples: (a) $5 \mathrm{~g}$ energetic projectiles; (b) $10 \mathrm{~g}$ energetic projectiles.

TABLE 3: Statistics of microcracks of coal samples.

\begin{tabular}{|c|c|c|c|c|c|c|c|}
\hline \multirow{2}{*}{$\begin{array}{l}\text { Coal } \\
\text { rank }\end{array}$} & \multirow{2}{*}{ Sample } & \multirow{2}{*}{$\begin{array}{l}\text { Loading } \\
\text { conditions }\end{array}$} & \multirow{2}{*}{$\begin{array}{l}\text { Impact } \\
\text { number }\end{array}$} & \multirow{2}{*}{$\begin{array}{c}\text { Linear } \\
\text { density }(\mathrm{mm})\end{array}$} & \multirow{2}{*}{$\begin{array}{c}\text { Areal } \\
\text { density }\left(\mathrm{mm}^{2}\right)\end{array}$} & \multicolumn{2}{|c|}{ Length between 0.625 and $20 \mathrm{~mm}$} \\
\hline & & & & & & Crack number, $N$ & Fractal dimension, $D$ \\
\hline \multirow{8}{*}{$\begin{array}{l}\text { Fat } \\
\text { coal }\end{array}$} & \multirow{5}{*}{ F1 } & \multirow{4}{*}{$5 \mathrm{~g}$ energetic projectiles } & 0 & 0.694 & 0.4025 & 161 & 1.810 \\
\hline & & & 4 & 0.784 & 0.8625 & 345 & 1.938 \\
\hline & & & 6 & 0.808 & 0.8375 & 335 & 1.716 \\
\hline & & & 10 & 0.867 & 0.97 & 388 & 1.679 \\
\hline & & \multirow{4}{*}{$15 \mathrm{~g}$ energetic projectiles } & 0 & 0.8 & 0.5375 & 215 & 2.007 \\
\hline & \multirow{3}{*}{ F3 } & & 2 & 0.922 & 0.5525 & 221 & 1.829 \\
\hline & & & 6 & 1.244 & 0.745 & 298 & 1.688 \\
\hline & & & 8 & 1.389 & 1.365 & 546 & 2.065 \\
\hline
\end{tabular}
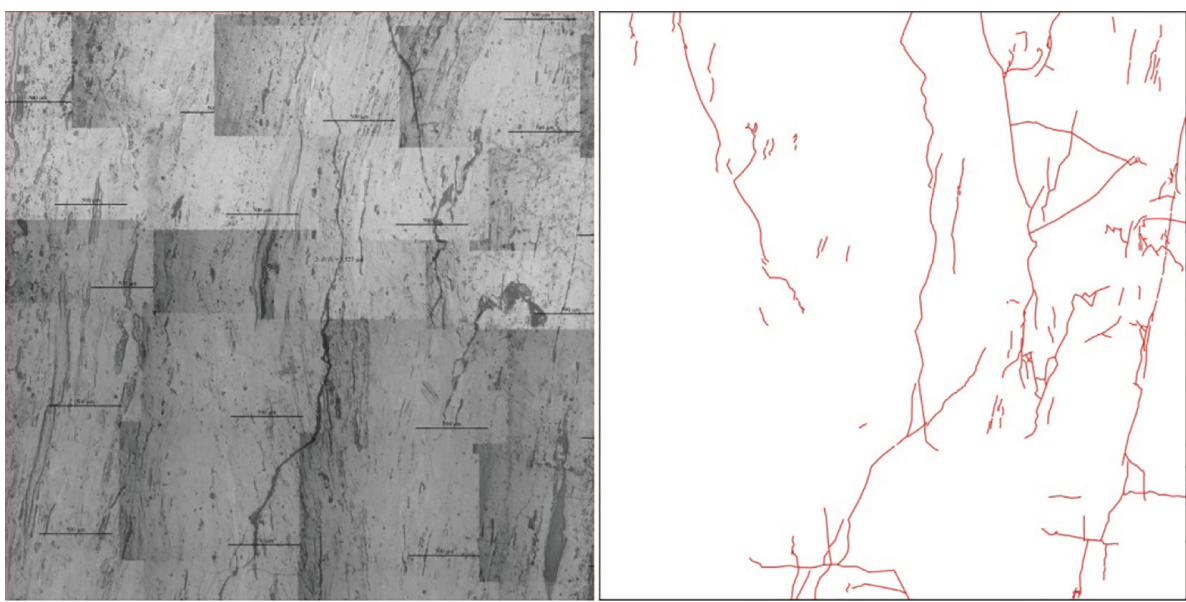

(a)

FIgURE 7: Continued. 

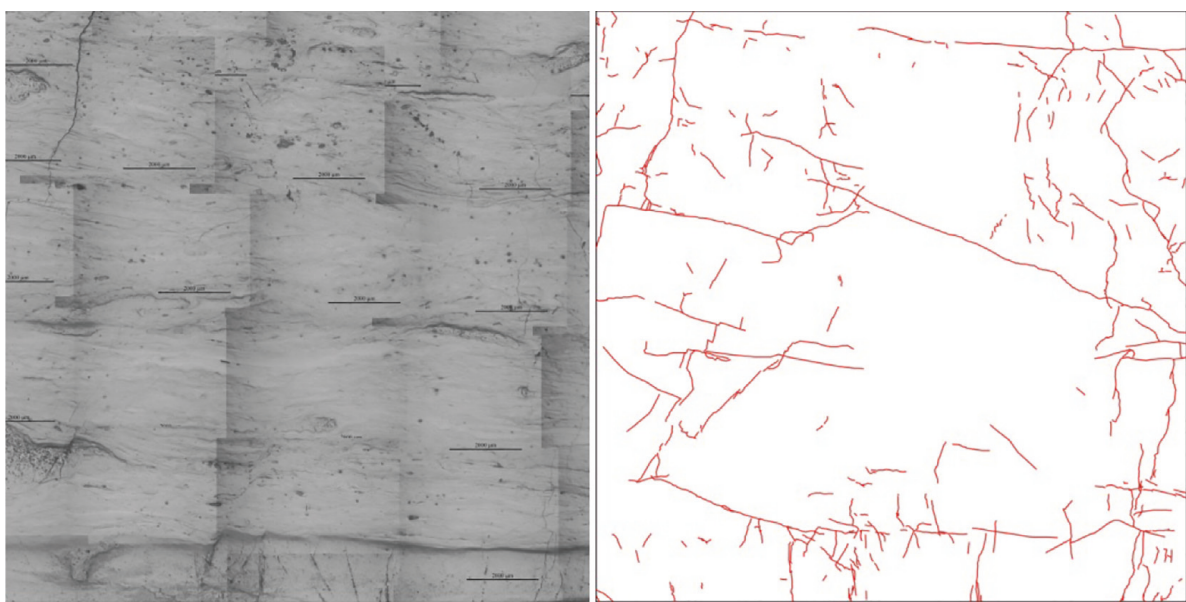

(b)
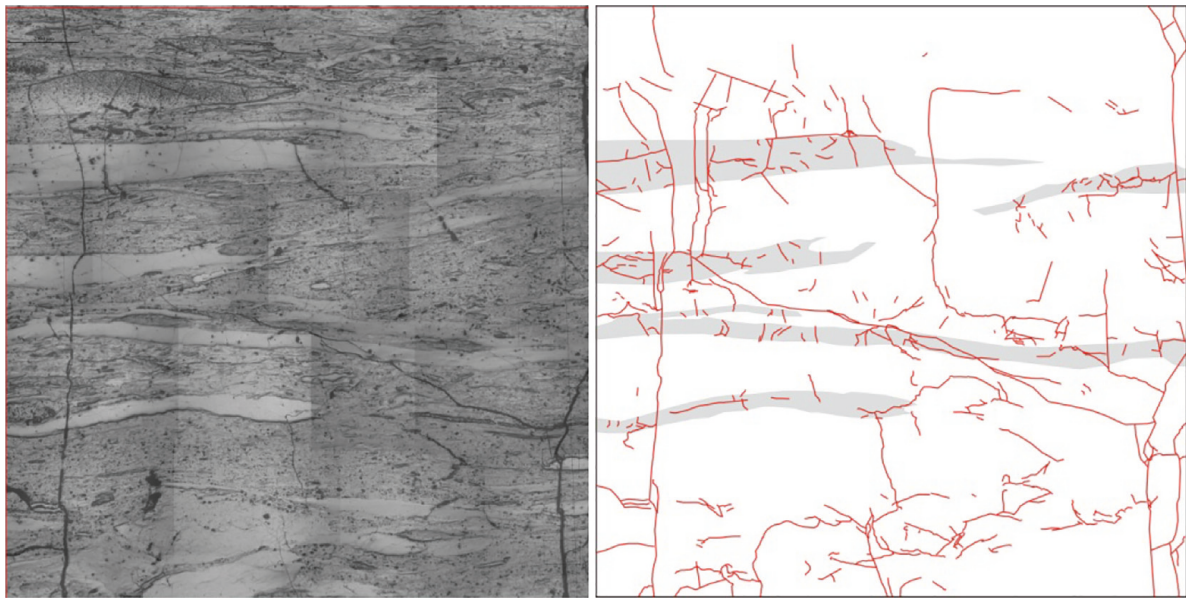

(c)

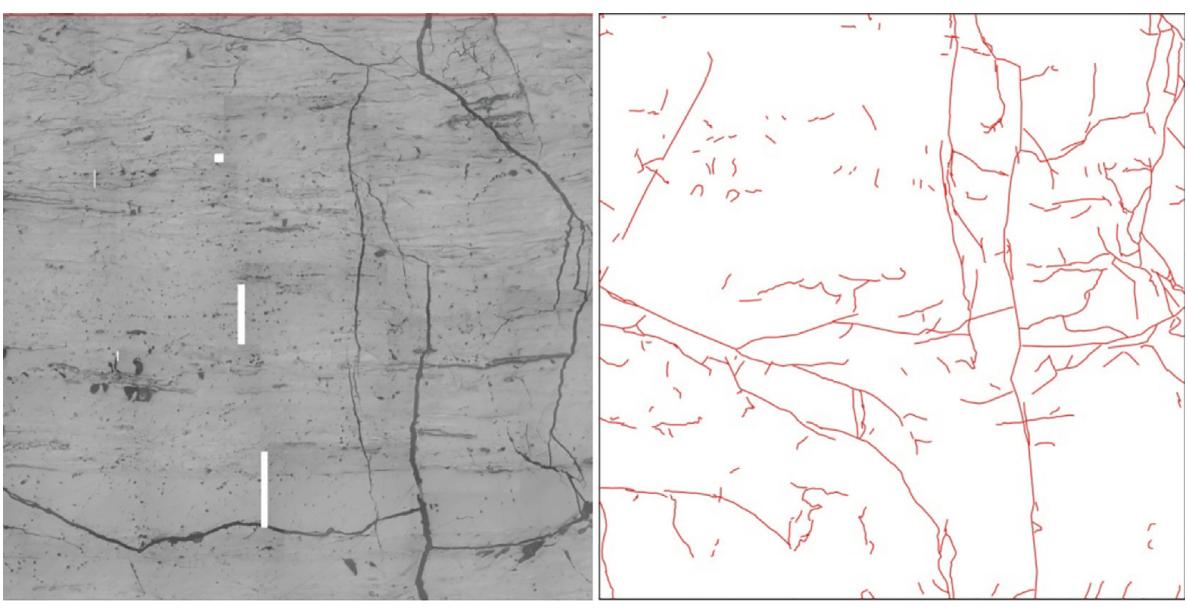

(d)

FIgURE 7: Continued. 


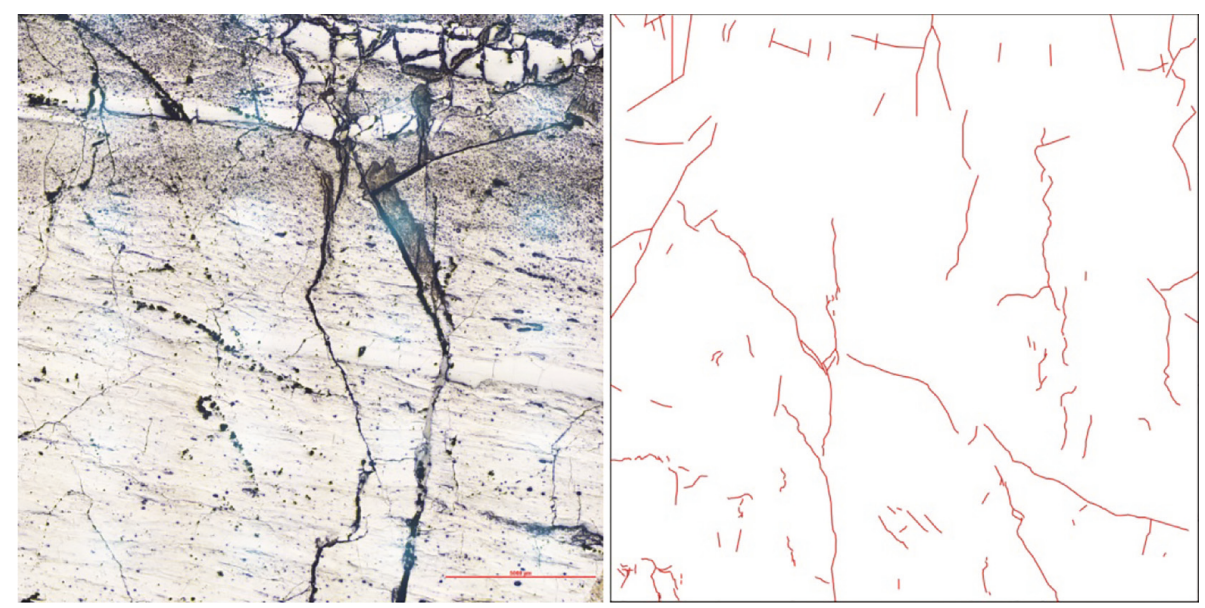

(e)

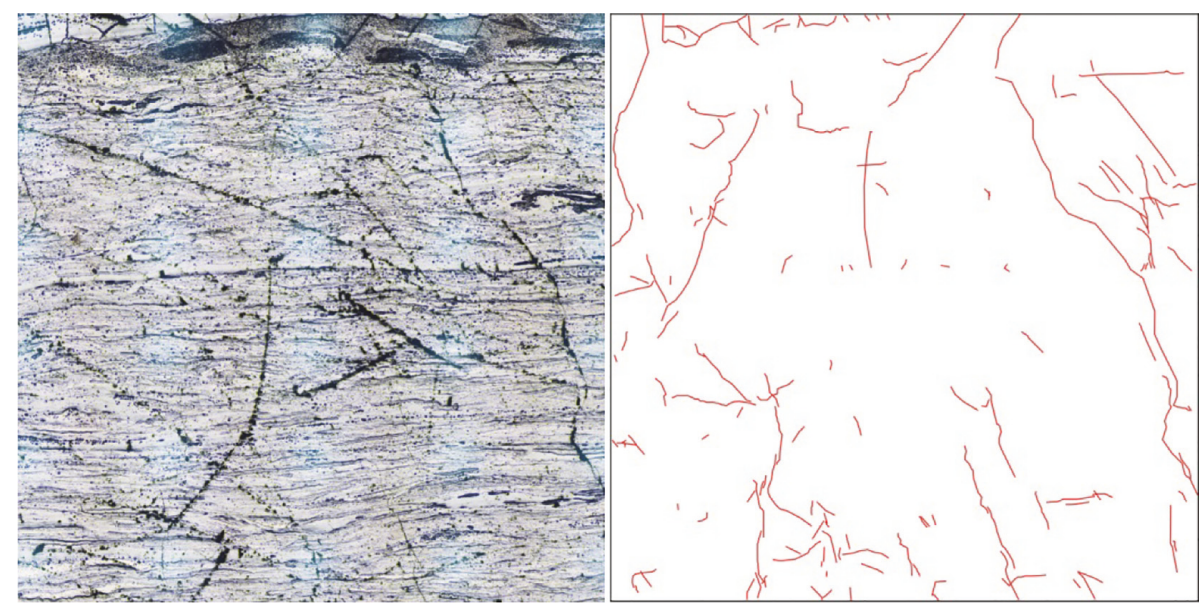

(f)
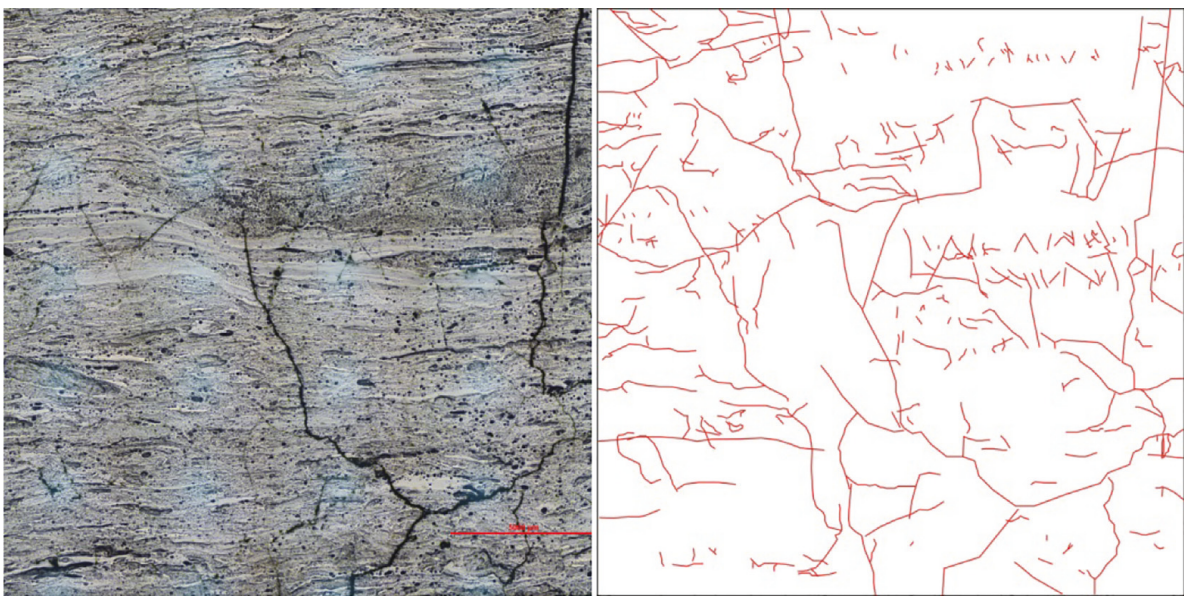

(g)

Figure 7: Continued. 

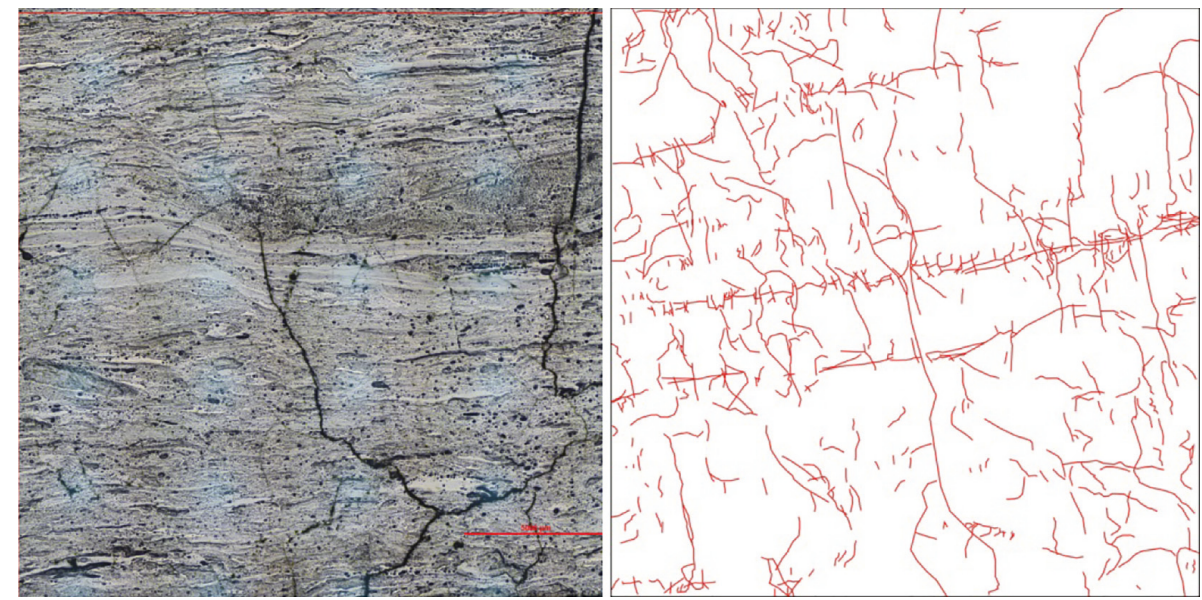

(h)

Figure 7: Evolution of microfractures in No. F1 and F3 fat coal samples (×20): (a) F1-0; (b) F1-4; (c) F1-6; (d) F1-10; (e) F3-0; (f) F3-2; (g) F3-6; (h) F3-8.

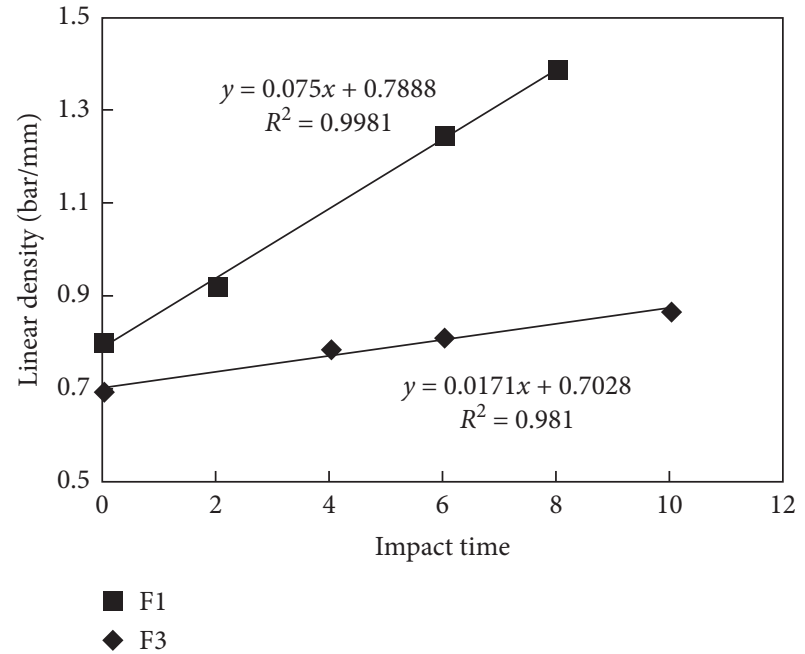

Figure 8: Plots of linear density to shock times for fat coal samples.

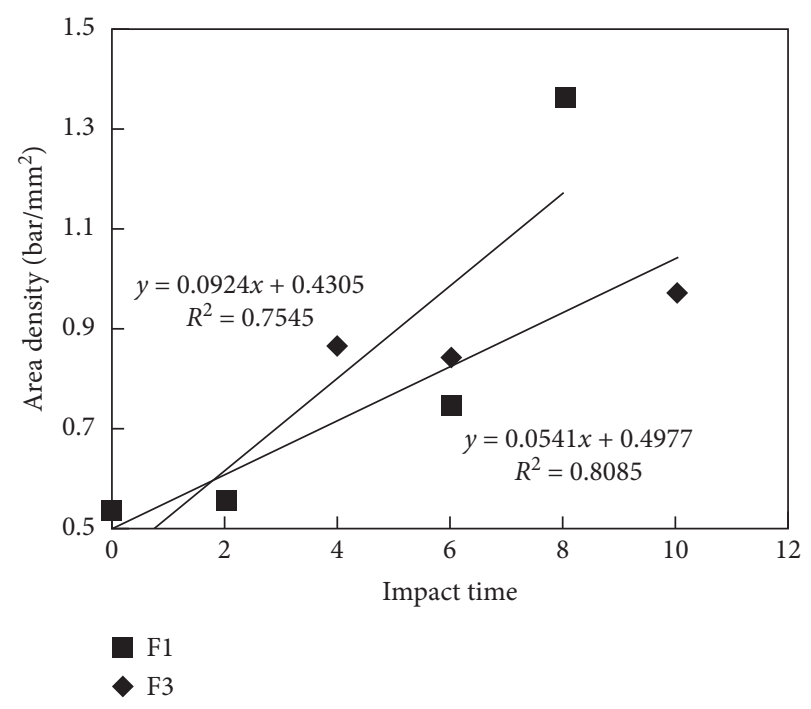

Figure 9: Plots of areal density to shock times for fat coal samples.

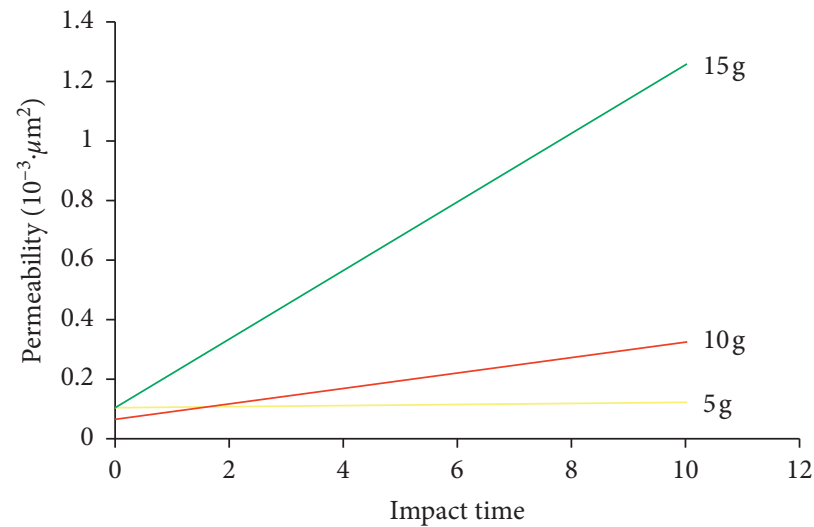

Figure 10: Testing results of porosity and permeability of coal samples.

\section{Conclusions}

Under repeated shock waves, the pore expansion of the coal body is carried out alternately with the development of large, medium, and small holes. The fluctuation trend of total pore volume is basically the same as that of micropores. The change of total pore volume mainly comes from micropores, and the impact can affect the expansion and development of micropores.

The microcracks of coal samples mainly began to germinate and develop from the telocollinite with more developed cracks. With the increase of impact times, cracks expanded through components and connected with each other and the length increases.

With different impact times, the number of microcracks increases and the length of cracks increases. The alternation of crack initiation and expansion makes the cracks develop continuously and improves the coal permeability.

\section{Data Availability}

The data used to support the findings of this study are available from the corresponding author upon request. 


\section{Conflicts of Interest}

The authors declare that there are no conflicts of interest regarding the publication of this paper.

\section{Acknowledgments}

Financial support for this work provided by the Scientific Research Fund of Jiangxi Provincial Education Department (nos. GJJ171489 and GJJ160567) is gratefully acknowledged.

\section{References}

[1] C. Zheng, M. Kizil, Z. Chen, and S. Aminossadati, "Effects of coal damage on permeability and gas drainage performance," International Journal of Mining Science and Technology, vol. 27, no. 5, pp. 783-786, 2017.

[2] Q. Liu, Y. Cheng, H. Wang et al., "Numerical assessment of the influences of coal permeability and gas pressure inhomogeneous distributions on gas drainage optimization," Journal of Natural Gas Science and Engineering, vol. 45, pp. 797-811, 2017.

[3] A. A. Osiptsov, "Fluid mechanics of hydraulic fracturing: a review," Journal of Petroleum Science and Engineering, vol. 156, pp. 513-535, 2017.

[4] J. Loomis and M. Haefele, "Quantifying market and nonmarket benefits and costs of hydraulic fracturing in the United States: a summary of the literature," Ecological Economics, vol. 138, pp. 160-167, 2017.

[5] D. Wei, Z. Gao, T. Fan, S. Wang, C. Li, and H. Li, "Experimental hydraulic fracture propagation on naturally tight intra-platform shoal carbonate," Journal of Petroleum Science and Engineering, vol. 157, pp. 980-989, 2017.

[6] P. Hou, F. Gao, Y. Ju, Y. Yang, Y. Gao, and J. Liu, "Effect of water and nitrogen fracturing fluids on initiation and extension of fracture in hydraulic fracturing of porous rock," Journal of Natural Gas Science and Engineering, vol. 45, pp. 38-52, 2017.

[7] E. E. Yost, J. Stanek, and L. D. Burgoon, "A decision analysis framework for estimating the potential hazards for drinking water resources of chemicals used in hydraulic fracturing fluids," Science of the Total Environment, vol. 574, pp. 15441558, 2017.

[8] R. Jeffrey, "Hydraulic fracturing for coal seam gas (CSG) stimulation in NSW," Report EP122949, CSIRO, Canberra, Australia, 2012.

[9] R. D. Balucan, L. G. Turner, and K. M. Steel, "Acid-induced mineral alteration and its influence on the permeability and compressibility of coal," Journal of Natural Gas Science and Engineering, vol. 33, pp. 973-987, 2016.

[10] B. Huang, J. F. ChangyouLiu, J. Fu, and H. Guan, "Hydraulic fracturing after water pressure control blasting for increased fracturing," International Journal of Rock Mechanics and Mining Sciences, vol. 48, no. 6, pp. 976-983, 2011.

[11] C. Lan, "Increasing suction quantity of firedamp by long hole blasting in crossing," Safety in Coal Mines, vol. 34, no. 8, pp. 14-15, 2003.

[12] P. Xu, Y. Cheng, G. Wang et al., "Predicting reservoir permeability that improved through explosion fracturing by means of artificial neural network," in Proceedings of the Third Pacific-Asia Conference on Circuits, Communications and System (PACCS), Wuhan, China, July 2011.

[13] F. Cai, Z.-G. Liu, B.-q. Lin, and W. Li, "Numerical simulation and experiment analysis of improving permeability by deep- hole presplitting explosion in high gassy and low permeability coal seam," Journal of Coal Science and Engineering (China), vol. 15, no. 2, pp. 175-180, 2009.

[14] G. De-yong, L. Peng-fei, P. Hai-bo et al., "Numerical simulation on crack propagation of coal bed deep-hole cumulative blasting," Journal of China Coal Society, vol. 37, no. 2, pp. 274-279, 2012.

[15] F. Ren, L. Ge, T. E. Rufford, H. Xing, and V. Rudolph, "Permeability enhancement of coal by chemical-free fracturing using high-voltage electrohydraulic discharge," Journal of Natural Gas Science and Engineering, vol. 57, pp. 1-10, 2018.

[16] M. Chao-min, R. Hui-qi, L. Yong-chi et al., "Propagation laws of blast wave in saturated soils with high saturation degree," Rock and Soil Mechanics, vol. 31, no. 3, pp. 875-880, 2010.

[17] W. Liang, L. Wen-bo, and Z. Qi, "Distribution of explosive energy consumed by column charge in rock," Rock and Soil Mechanics, vol. 27, no. 5, pp. 736-739, 2007.

[18] J. Yang, W. Gao, and Q. Jin, "Experiment on dynamic damage property of rock and new damage model for rock fragmentation by blasting," Chinese Journal of Rock Mechanics and Engineering, vol. 20, no. 3, pp. 320-323, 2001.

[19] P. Xu, Y. Cheng, X. Liu, X. Zhang, and L. Shi, "Explosive fracturing simulation experiment for low permeability reservoirs and fractal characteristics of cracks produced," $P e$ troleum Exploration and Development, vol. 40, no. 5, pp. 682-686, 2013.

[20] Y.-S. Lin, Z. Tian-yu, J. Jin-bao et al., "Numerical simulation analysis of effect on the cement sample by blast wave in the water," Explosion and Shock Waves, vol. 26, no. 5, pp. 462467, 2006.

[21] F. Xuehai, Q. Yong, X. Xiuqian et al., "Research on fractals of pore and fracture-structure of coal reservoirs," Journal of China University of Mining \& Technology, vol. 30, no. 3, pp. 11-14, 2001. 


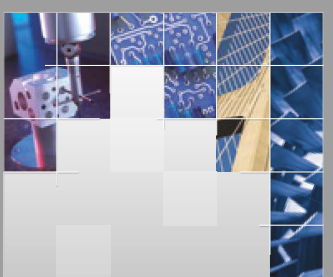

\section{Enfincering}
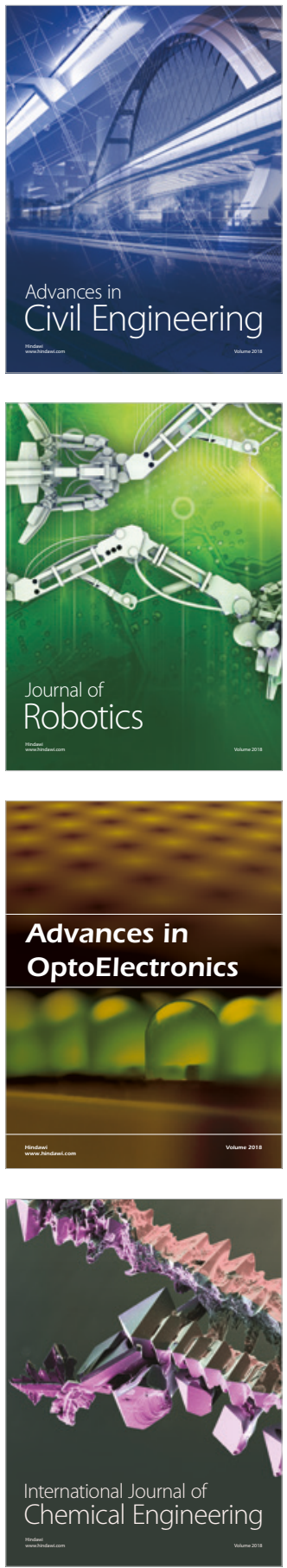

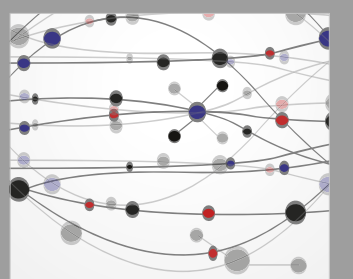

\section{Rotating \\ Machinery}

The Scientific World Journal

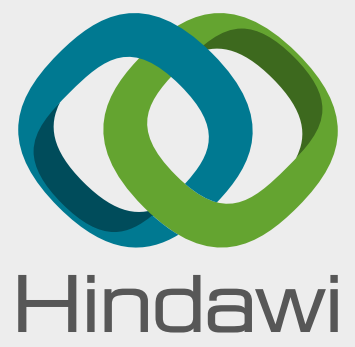

Submit your manuscripts at

www.hindawi.com
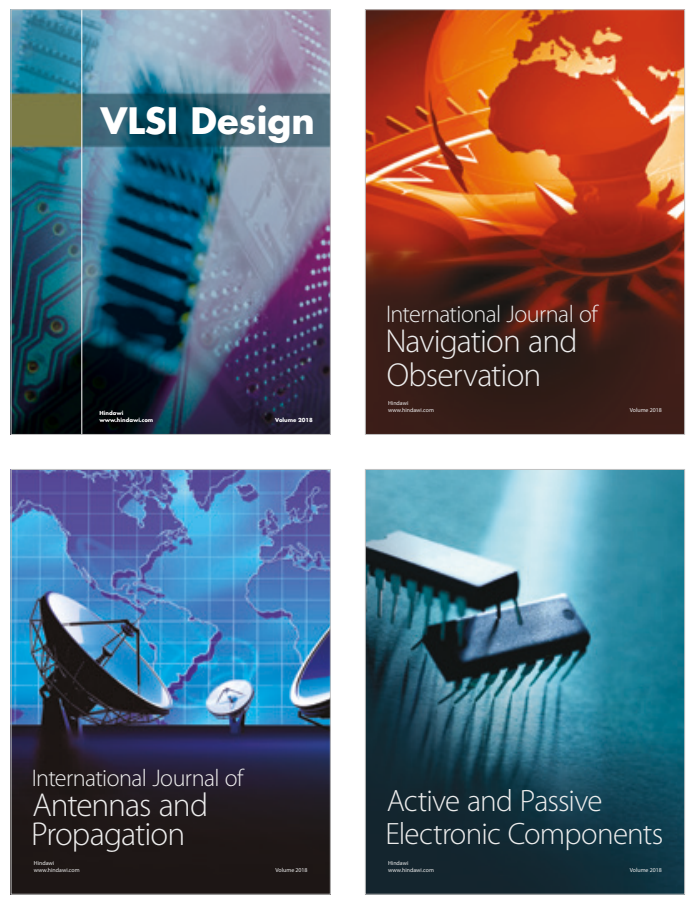
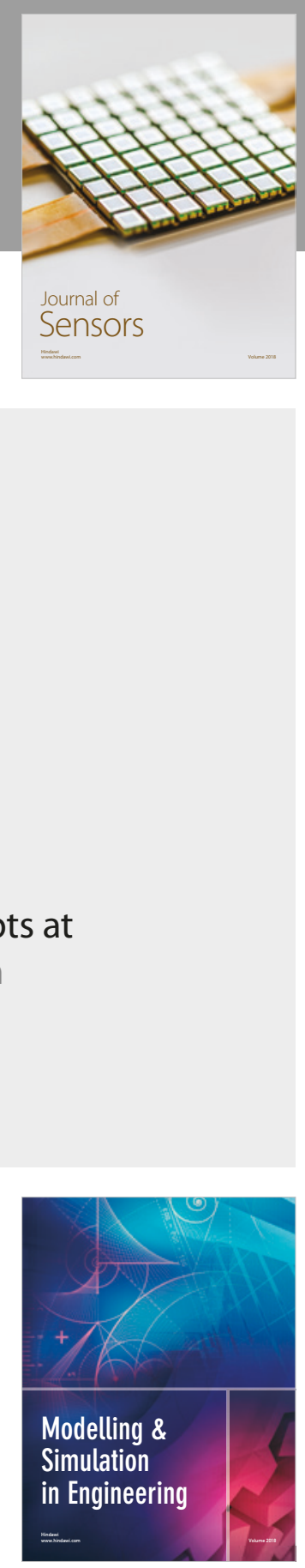

\section{Advances \\ Multimedia}
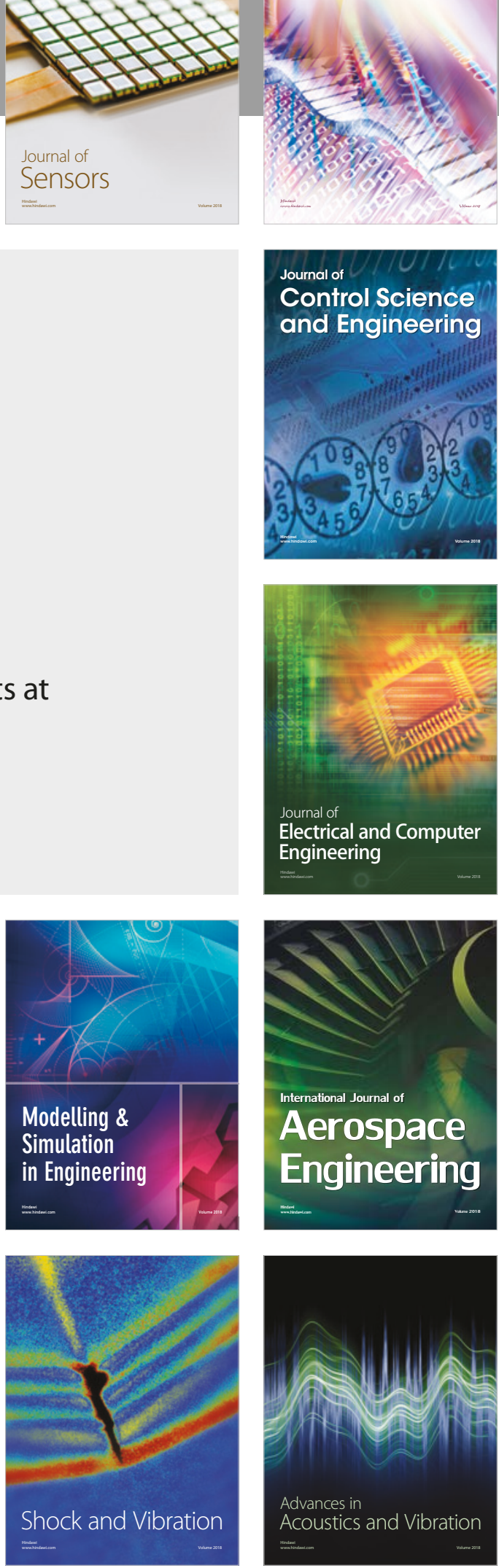